\title{
O papel do professor universitário, a universidade e as condições de saúde no trabalho: um convite à reflexão
}

\author{
The role of the university professor, the university and health \\ conditions at work: na invitation to reflection
}

\author{
Queli Ghilardi Cancian ${ }^{1 *}$, Andréia Florêncio Eduardo de Deus ${ }^{1}$, \\ Ricardo da Cruz Monsores ${ }^{1}$, Vilmar Malacarne ${ }^{1}$
}

\begin{abstract}
RESUMO
As universidades representam para a sociedade o desenvolvimento, através da construção científica e crítica do conhecimento. Neste ambiente, o debate que envolve a construção de políticas públicas sobre a qualidade de vida e saúde suscita o diálogo entre seus inúmeros atores sociais. Nesta arena, o professor universitário ganha destaque na mediação entre os saberes científicos e a comunidade acadêmica, que por sua vez contribui para o desenvolvimento socioeconômico e cultural de uma região. O professor, universitário mediante o cumprimento de suas funções, vem, contudo, se sobrecarregando, comprometendo a própria saúde. Dia após dia o professor vem assistindo o declínio da sua qualidade de vida e de saúde, motivado pelas inúmeras obrigações e pela falta de políticas públicas que os amparem preventivamente diante de suas vulnerabilidades físicas e psicológicas, cenário que foi extremamente agravado pela pandemia do Covid19. Considerando o ambiente de trabalho como influenciador na qualidade de vida e saúde dos seres humanos, o objetivo deste artigo é trazer algumas reflexões e questionamentos sobre a universidade e as políticas públicas frente a esse processo de vulnerabilidade docente, utilizando como base metodológica as revisões bibliográficas de artigos e de livros. A construção bibliográfica deste estudo aborda as costuras que permeiam a educação e a saúde, o ser professor e a função das universidades na sociedade enfatizando o professor e sua condição de trabalho, de saúde e qualidade de vida. Fica clara a estreita e frágil ligação de interdependência entre a saúde e trabalho do professor universitário a ausência do olhar do estado para tal condição e os riscos que ela expõe.
\end{abstract}

Palavras-chave: Professor universitário; Qualidade de vida; Universidade; Vulnerabilidade docente.

\begin{abstract}
The universities represent for society the development through a scientific and critical construction of knowledge. In this environment, the debate involving the construction of public policies on quality of life and health raises dialogue between its many social actors. In this arena, the university professor gains prominence in the mediation between scientific knowledge and the academic community, which contributes to the economic and cultural socio-development of a region. The functions of the university professor have been overloading, compromising his health. Day after day the teacher has been witnessing the decline of his quality of life and health, motivated by the many obligations and the lack of public policies that parse them preventively in the face of their physical and psychological vulnerabilities. Considering the work environment as an influencer in the quality of life and health of human beings, this article aims to bring some reflections and questions about the university and public policies in the face of this process of
\end{abstract}

\footnotetext{
${ }^{1}$ Universidade do Oeste do Paraná - UNIOESTE. *E-mail: quelicancian@gmail.com
} 
vulnerability of using bibliographic reviews of articles and books as a methodological basis. The bibliographic construction of this study brings a panoramic approach to being a teacher and the role of universities in society and on the professor and his working condition, health, and quality of life.

Keywords: University professor ; Quality of life; University; Teacher vulnerability

\section{INTRODUÇÃO}

A universidade fabrica e coparticipa suas próprias reflexões. É no espaço universitário, mais propriamente no trabalho materializado em ações e discussões desenvolvidas e conduzidas pelos professores, que surgem os pensamentos e as concepções diversas que colaboram sensivelmente para o desenvolvimento da sociedade.

Considerando a importância da universidade na construção de um processo histórico, retomamos o sentido de pertencimento social que ela permite estabelecer na universalidade do saber e do agir dos homens. Assim, é importante compreender o papel das instituições de ensino como espaço de saber universal, mediadas pelas relações de poder político e ações públicas (PIMENTA et al., 2003).

A construção do conhecimento se dá pelo processo de ensino/aprendizagem, que se concretiza por três pilares que sustentam o conhecimento acadêmico universitário o ensino a pesquisa e a extensão (SLEUTJES, 1999). Da mesma forma, a interação entre universidade, professores e acadêmicos promove o aprendizado na perspectiva de construção e reconstrução do conhecimento e o desenvolvimento sociocultural de uma sociedade (PIMENTA et al., 2003 e KOETZ, 2011). Neste escopo, constitui-se o professor universitário é identificar-se como agente ativo na construção e reconstrução de saberes promovendo ações críticas e reflexivas que influenciem na transformação social do seu meio. Porém, ao desenvolver tais funções o professor se depara com inúmeras tarefas e obrigações que perpassam o objetivo primário do seu trabalho.

A construção do conhecimento dentro do meio universitário tomou características avaliativas tanto institucional como profissional, ou seja, cada instituição e cada docente é avaliado de acordo como o seu número de produção acadêmica, o que frequentemente é confundido como qualidade. Na busca por boas avaliações e consequente avanço profissional o professor acaba por assumir multitarefas fato que não tem contribuído para um ambiente de trabalho motivador, além disso a carga de trabalho 
cada vez mais alta tem ocasionado comprometimento da saúde física e psicológica, como também nas interações sociais e pessoais de diversos professores.

No desenvolvimento deste artigo serão apresentadas indagações por meio da perspectiva interacionista, tais como: Como os professores percebem as políticas educacionais nas universidades? O professor tem autonomia diante destas políticas? As constantes mudanças que envolvem o meio acadêmico comprometem a qualidade de vida e saúde dos professores? As crescentes e diferentes demandas causam sobrecarga de trabalho? Com se dão as relações interpessoais no ambiente de trabalho? Quais são as condições físicas "estruturais" do ambiente de trabalho? Como está a saúde psicológica do professor?

Tais indagações possibilitam uma reflexão sobre a temática, o objetivo central desta discussão é embarcar sob algumas perspectivas de interação entre o papel da universidade, do professor universitário e as condições de saúde desses profissionais, disponibilizando alguns questionamentos, a fim de conduzir um convite à reflexão ao leitor sobre a universidade e as políticas públicas frente a esse processo de vulnerabilidade do docente.

\section{PERCURSO METODOLÓGICO}

Para realização das reflexões aqui apresentadas realizamos um estudo bibliográfico descritivo de cunho reflexivo. O objetivo da pesquisa bibliográfica é buscar, por meio da revisão da literatura, a contribuição cultural e científica sobre determinado assunto, tema ou problema (CERVO; BERVIAN; DA SILVA, 2007).

Para realizar a busca dos textos relativos à temática, foram utilizados os descritores "professores universitários, universidades, qualidade de vida, carga de trabalho docente, saúde laboral e saúde psicológica”. As bases de dados consultadas foram: Lilacs, Cielo e Google Acadêmico.

Para criar um arcabouço metodológico, foram seguidas as orientações propostas por Cervo et al. (2007), que se constitui primeiramente na leitura exploratória, em seguida a leitura seletiva, posteriormente a leitura crítica e por fim a leitura interpretativa. Neste percurso metodológico busca-se explorar os textos selecionados num processo investigativo almejando construir uma linha de pensamento sobre o tema escolhido. 


\section{A UNIVERSIDADE E O PAPEL DO PROFESSOR UNIVERSITÁRIO}

O presente item não vem discutir a história e a constituição da universidade brasileira, e sim apresentar algumas conjecturas relacionadas ao ensino, a Ciência, a crítica, a cultura e ao papel do professor. Na teoria, as universidades possuem o intuito de ir além desses tópicos, tais como a conscientização de educadores e de autoridades públicas quanto aos problemas intrínsecos à educação, entre outros tantos.

As universidades possuem um papel fundamental na construção de um país, seu processo histórico se confunde com o desenvolvimento social e econômico, na formação crítica e competente do cidadão (KOETZ, 2011).

Na compreensão que a Universidade é um serviço de educação que se concretiza pela docência e investigação, Pimenta et al., sintetiza suas funções em:

Criação, desenvolvimento, transmissão e crítica da ciência, da técnica e da cultura; preparação para o exercício de atividades profissionais que exijam a aplicação de conhecimento e métodos científicos e para a criação artística; apoio científico e técnico ao desenvolvimento cultural, social e econômicos das sociedades (PIMENTA et al., 2003, p.270).

O papel da Universidade na sociedade, está na construção científica e crítica do conhecimento, de forma que o ensino passa a possuir características que vão além do processo ensino/aprendizagem, abrangendo um conjunto de domínio de conhecimentos, técnicos, científicos, metodológicos, que colaboram no desenvolvimento das capacidades reflexivas, no conhecimento cultural, nas atividades de integração e investigação, promovidas pelo processo interativo e participativo entre professor/aluno (PIMENTA et al., 2003).

Zabalza (2004), descreve que o papel das universidades ultrapassa as barreiras da simples transmissão de conhecimento científico, com a necessidade de produzi-lo e socializá-lo. Sua função contribui em avanços qualitativos, potencializando a relação com o meio social, econômico e profissional, cuja melhoria é necessária e precisa acontecer.

As atribuições das universidades, em um sentido mais amplo, voltam-se para cotizar-se na preparação das novas gerações que conduzirão o país, a sociedade, a educação, o que significa dizer que sua função está além da preparação de novos e inovadores profissionais para o mercado (DEMO, 2008). Deste modo, as universidades são constantemente cobradas por um novo modelo social que se alastra por todo o mundo impulsionado pelo processo de globalização. Rapidamente, as novas práticas sociais são 
inseridas na arena da educação superior, reformando sua organização e suas discussões sobre o funcionamento das instituições de modo geral, prioritariamente, das universidades públicas (LOPES, 2006).

O papel do professor imerso no universo político e social constrói-se pelo processo ensino/aprendizagem ao mesmo tempo em que contribui na construção de conhecimentos. "Sendo o professor um ator político e social ativo, espera-se que o mesmo intervenha e reformule a sua prática de forma autônoma, responsável, consciente e participativa" (SOLIGO, 2010, p.121).

Alguns aspectos impulsionam o professor universitário no desenvolvimento da profissão. Pimenta et al., descreve tais aspectos como:

[...] a transformação da sociedade, seus valores e suas formas de organização e de trabalho; o avanço exponencial da ciência nas últimas décadas; a consolidação progressiva de uma ciência da educação possibilitando a todos o acesso aos saberes elaborado no campo da pedagogia (PIMENTA et al.,2003 p.271).

As complexidades encontradas pelo professor no cumprimento de sua função, remetem-se a constante reflexão sobre a sua prática pedagógica, diante da condição e dos limites do próprio contexto educacional (SOLIGO, 2010).

Porém, é comum que o olhar da sociedade para o professor não seja o de reconhecimento de um profissional, mas a busca por um ser apaixonado pelos afazeres que a formação lhe trouxe e este entendimento acaba por camuflar aspectos importantes da vida deste profissional, como condições de trabalho colocadas pelo sistema e saúde física e psicológica uma relação próxima e muitas vezes conflitantes.

\subsection{0 professor universitário e as suas atribuições}

$\mathrm{O}$ século $\mathrm{XX}$ foi marcado por grandes mudanças tecnológicas e sociais, que estimularam uma série de transformações estruturais, econômicas, sociais e políticas. A globalização trouxe consigo mudanças que afetaram os hábitos dos seres humanos que agora têm milhares de coisas para preencher sua vida diária (SILVA, 2006; PRIESS, 2012).

Sem a presunção de relacionar e debater todos os princípios da correlação e do dinamismo que o tema desse item proporciona, tem-se, ao se refletir o exercício da função de professor universitário, uma imensa dimensionalidade de responsabilidades, necessidades diversas e funções. 
Pimenta (2012), considera que o trabalho desenvolvido pelo professor não pode ser fragmentado, o mesmo deve ser considerado em sua totalidade. Deste modo, o trabalho do professor não se limita ao processo de ensinar conteúdos técnicos e científicos, mas assume no contexto um papel social diante da formação de pessoas capazes de desenvolver um pensamento crítico e social abarcando assim em suas atribuições olhares para além da profissão. Mercado descreve os professores como:

Profissionais que tem uma função re(criadora) sistemática, sendo está a única forma de proceder quando se tem alunos e contextos de ensino com características tão diversificadas, como sucede em todos os níveis de ensino. A função do professor é a criação e recriação sistemática, que tem em conta o contexto em que se desenvolve a sua atividade e a população-alvo desta atividade (MERCADO, 1998, p.03).

Neste sentido o desenvolvimento do trabalho docente depende do contexto social em que está inserido da sua própria realidade.

Ospina, (1990), considera que o trabalho das universidades, em um sentido mais amplo, refere-se à transformação da sociedade através do conhecimento humano. $\mathrm{O}$ autor ainda considera que as funções que sustentam o desenvolvimento do conhecimento se dão através do tripé ensino, pesquisa e extensão.

Considerando o tripé que sustenta o processo de formação universitária, temos o ensino como ato de ensinar, as pesquisas como ação de investigação e a extensão como o exercício social. Partindo desta premissa, compreende-se que o ensino universitário contempla não somente a (re)construção de conhecimento em sala, mas sim a investigação (pura ou aplicada), e ação que extrapola os muros da universidade (SLEUTJES, 1999). E toda essa gama de atividades proporcionadas no ambiente universitário são propostas por professores.

Diante de tantas exigências atribuídas ao professor universitário no desenvolvimento de suas funções, Lopes considera que há uma:

Precarização do trabalho docente, descompromisso e desfinanciamento contínuo por parte do Estado, venda de "mercadorias-conhecimento" (assessorias, pesquisas, produtos técnicos...) para entidades privadas, constituição de complexos processos avaliativos definidores de benefícios, dentre outros aspectos, tornam-se alicerces do ensino superior. Todo um conjunto de novos aparatos e mecanismos de motivação e controle, toda uma nova lógica de gestão/produção (produtividade) toma corpo no interior da universidade (LOPES, 2006, p.36).

O professor está envolto em um movimento de rápidas transformações, onde se vê mergulhado em constantes mudanças no seu dia a dia no trabalho, se encaixando num 
sistema competitivo e continuo na produção de formandos, artigos, extensões entre outras, as quais têm o objetivo de atender de forma rentável, o sistema organizacional socioprodutivo (LOPES,2006).

Zabalza (2004) descreve a função do professor universitário a partir de três dimensões: profissional, pessoal e administrativa, o que torna essa uma profissão complexa. Neste contexto em que se constrói a profissão por vezes o próprio professor não se compreender com tal na dimensão profissional quando, por exemplo, se declara profissional de qualquer outra área e não o professor que ensina pra tal formação. (ZABALZA, 2004), Tal condição pode estar ligado aos diferentes ações e concepções que permeiam as dimensões colocadas pelo autor.

Os requisitos demandados no meio acadêmico, exigem do professor constante formação e atualização. Assim como em qualquer profissão acompanhar as mudanças na área profissional é uma necessidade nem sempre atendida, essa quase ausência de formação constante fato evidenciado no cenário atual e uma clara ausência de estado em proporcionar tais capacitações deixando a cargo do professor mais esta tarefa.

O ambiente de trabalho pode ser fator que influência na qualidade de vida do ser humano. No caso do professor universitário embora muitas vezes não perceba, está exposto a diversos fatores que podem comprometer sua saúde física e mental e refletir na vida e relacionamentos interpessoais e sociais.

A atividade docente foi marcada por grandes desafios, reflexo das diversas modificações que ocorrem através do processo de globalização do trabalho. As multitarefas que fazem parte das funções do professor, somadas a outros fatores internos e externos ao ambiente de trabalho, tem contribuído para o adoecimento físico e mental de um grande número de professores (CRUZ et al. 2010).

Partindo dos desafios lançados no mundo contemporâneo o professor se vê mergulhado em um apanhado de obrigações que transcendem as salas de aula, obrigandose por inúmeras vezes a cumprir suas tarefas após o horário de expediente. Essa jornada estendida acaba sobrecarregando a rotina de trabalho.

Percebe-se que há necessidade de uma compreensão maior da atividade do professor universitário, do acompanhamento desse trabalho, que está em construção contínua de suas atribuições e em busca constante no esforço de satisfazer diversas exigências, que resultam num prejuízo à saúde desses profissionais, assim sendo, o próximo item traz uma abordagem relacional entre o trabalho e a saúde dos docentes 
universitários.

\subsection{O trabalho e a saúde dos professors universitários}

O trabalho é a atuação essencial dos seres humanos e, assim, corrobora no seu crescimento e desenvolvimento como espécie. A frente de um mundo crescentemente mais interligado e globalizado, primordialmente, os procedimentos de trabalho têm passado por diversas transformações, o que de certa forma reflete também de modo negativo na saúde mental e física dos trabalhadores. Trata-se de uma complexa conjuntura. Nesse sentido, o presente item traz algumas circunstâncias relacionadas as atribuições dos professores universitários, assim como da universidade, citados nos tópicos anteriores, pois esses contextos estão totalmente entrelaçados.

O trabalho entre outras coisas tem função social na vida humana, além disso exerce papel importante também em questões pessoais do ser humano. É normal que dediquemos pelo menos um terço do nosso dia ao cumprimento das atividades relacionadas ao trabalho, aonde vivenciamos diversas experiências, as quais podem influenciar no desenvolvimento do próprio trabalho ou ainda se estender para a vida pessoal e social (SILVA, 2006; DOS SANTOS SOUZA, 2015; DOS SANTOS e DA SILVA, 2017).

O ambiente de trabalho na universidade tem, também, refletidas as concepções do modo de produção capitalista a qual estão submetidos grande parte dos países. Por meio da cobrança acentuada de produtividade os professores são de certa forma induzidos a realizarem suas atividades laborais mesmo em períodos que seriam de repouso e lazer. Isso tudo requer deste profissional uma maior dedicação afetiva para a sua realização, pois está frequentemente expondo o seu trabalho a críticas a comunidade acadêmica. (SORATO e OLIVIER-HECKLER, 1999).

A profissão de professor universitário não é uma função exclusiva para muitos profissionais, pois muitos atuam em diversas outras áreas ligadas ou não a sua formação. Primordialmente porque muitos professores universitários têm sua formação inicial com bacharéis em outras áreas e por diversas motivações se tornaram também professores a exemplo disso citamos os profissionais médicos, engenheiros, advogados, arquitetos, enfermeiros... (SILVA, 2006).

Faz parte da função do professor universitário as multitarefas que envolvem ensino, pesquisa e extensão, e que no seu desenvolvimento se desdobram em vários 
processos de interações entre grupos de trabalho, alunos, orientações, projetos etc., além destas, o professor precisa também desempenhar atividades de cunho administrativo que envolvem capacitações, reuniões, comissões, entre outras (PRIESS, 2011). Dentre as motivações para a gama de trabalho a ser desenvolvida pelo professor universitário está o fato de que no Brasil ainda o desenvolvimento tecnológico e científico é produzido primordialmente pelas universidades conduzido pelos professores.

Neste sentido, as inúmeras tarefas que contemplam o plano de ensino/aprendizagem têm exigido muito da saúde física, psicológica e social dos professores. As inúmeras exigências metodológicas e científicas, impostas pelo atual modelo produtivo das universidades tem ocasionado uma carga extra de trabalho na vida diária do professor, que o obriga a estender a jornada de trabalho a fim de cumprir as demandas apresentadas. (BORSOI, 2012; DOS SANTOS, 2017).

Para Leda e Mancebo (2009), o grande rol de atividades que compõe as funções do docente, geram uma carga de trabalho que ultrapassa os murros das instituições, indo além da carga horaria de 40 horas semanais ou mesmo aqueles que são concursados no regime de dedicação exclusiva. A consequência é perceptível por meio do cansaço, desanimo, ansiedade, se concretizando nas doenças relacionadas ao trabalho, tais limitações variando de acordo com o ritmo e as capacidades de enfrentamento de cada sujeito.

Outro ponto negativo são as constantes mudanças no ambiente universitário, que nem sempre são favoráveis. Borsoi, destaca que,

[...] a reestruturação universitária não tem contemplado mudanças efetivas das condições laborais e tem, sobretudo, resultado em intensificação do trabalho docente, uma vez que o aumento do contingente de docentes não se dá na mesma proporção em que se expandem as demandas de trabalho (BORSOI, 2012, p. 82).

Sobre esta ótica compreende-se que a relação do trabalho está intimamente ligada a qualidade de vida, na condição de saúde e bem-estar, frente a cumprimento das funções. $\mathrm{O}$ conceito de qualidade de vida no trabalho refere-se diretamente aos aspectos físicos e ambientais, psicológicos e sociais (ROHDE, 2012). Segundo a Lei 8080/90, a saúde é um direito fundamental do ser humano.

Art. II É o dever do Estado de garantir a saúde consiste na formulação e execução de políticas econômicas e sociais que visem à redução de riscos de doenças e de outros agravos e no estabelecimento de condições que assegurem acesso universal e igualitário às ações e aos serviços para a sua promoção, 
proteção e recuperação. (BRASIL, 1990).

Assim sendo, a saúde em sua forma plena deveria completar o bem-estar total, sem privações e limitações inerentes a condição social, racial ou religiosa do sujeito. Segundo Silva (2006) a Organização Mundial da Saúde (OMS), salienta que a saúde é "um completo estado de bem-estar físico, mental e social, que consiste não apenas em ausência de doença ou enfermidade", (SILVA, 2006, p.28).

Ainda em conformidade com a OMS Amaro e Dumith (2018) descrevem a qualidade de vida como "a percepção do indivíduo de sua posição na vida no contexto da cultura e sistema de valores nos quais ele vive e em relação aos seus objetivos, expectativas, padrões e preocupações" (AMARO; DUMITH, 2018, p.95).

A qualidade de vida e a saúde estão associadas ao estilo de vida adotado pelo sujeito ou imposto a ele, que por sua vez está relacionada a construção cultural de uma sociedade, se justificando através da atitude e do comportamento desenvolvido. A adoção de práticas de exercícios físicos, hábitos alimentares saudáveis, tempo de descanso e lazer proporcionam maior qualidade de vida e reduzem a incidência de doenças (PRIESS, 2011).

Nahas (2003), chama a atenção para a adoção de um estilo de vida saudável, através de atividades físicas regulares e nutrição equilibrada. $\mathrm{O}$ autor destaca que embora exista inúmeras evidências científicas que comprovem que o estilo de vida influencia na qualidade de vida e saúde, as pessoas demostram desinteresse ou desinformação, sobre o assunto e também dos seus efeitos a médio e longo prazo. Desta forma “os contextos de trabalho podem atuar como fonte de saúde ou de adoecimento tanto com respeito à saúde geral quanto à saúde mental”. (Seligmann-Silva 2011, p.34). Assim, as turbulências do ambiente de trabalho, associadas ao estilo de vida e as condições biológicas dos indivíduos, pode ser caracterizada como uma bomba de alto poder destrutivo prestes a explodir.

Guilhardi (2002), chama a atenção para outro aspecto importante neste contexto, as políticas públicas para a valorização dos professores. $\mathrm{O}$ autor destaca que existe um processo histórico de perdas de direitos, que envolvem a condição inadequada de trabalho que precisam ser debatidas e compreendidas.

A valorização do professor deve ocorrer a partir da formação de sua autoestima, cujo processo envolve o reconhecimento do docente pela relevância do seu papel social, e da autoconfiança, para que suas conquistas não sejam reconhecidas apenas no âmbito 
científico, mas que ocorra em uma totalidade partindo das conquistas realizadas diariamente em sala de aula (GUILHARDI, 2002).

\section{CONSIDERAÇÕES FINAIS}

A construção deste texto buscou seguir um olhar receptivo na tentativa de compreender e apresentar as relações no processo de formação profissional do professor universitário, por meio de uma chamada para reflexão e conscientização através da apresentação de argumentos e questionamentos quanto às condições de trabalho e saúde vivenciadas pelos professores nas universidades brasileiras, possibilitando uma maior nitidez nessas questões.

Pretendeu-se também contribuir para reflexão e construção de ideias que objetivam colaborar para abertura de discussão sobre o ser professor universitário na atual conjuntura do ensino superior no Brasil as suas atribuições e as suas vulnerabilidades diante do cumprimento de suas funções. Da mesma forma estimular o debate sobre as políticas públicas de valorização do docente e discutir ideias que possam servir de auxílio à construção de concepções que visem o desenvolvimento de um quadro geral sobre a dinâmica de produção, do desgaste ocasionado na situação do exercício da docência, e assim possibilitar a viabilização de medidas de prevenção necessárias ao bem-estar profissional, social e humano.

Diante do papel fundamental que as universidades desenvolvem, na construção de um país por meio de seu processo histórico e cultural, atuação e colaboração no desenvolvimento socioeconômico das regiões, destacamos como principal conquista a formação crítica e competente dos cidadãos.

Diante desta arena marcada por lutas e sofrimento, destacamos as conquistas e vitórias desse árduo caminho rumo a educação, neste ponto chamamos a atenção para os atores que viabilizam a construção e transmissão do conhecimento e dos saberes ao longo das gerações o professor.

Quem é o professor universitário? Qual é o seu papel mediante a construção de uma sociedade? Como está sua saúde e qualidade de vida? Enfim, são tantos questionamentos e ainda poucas respostas, mas neste momento busca-se uma reflexão sobre o professor como ser social, que possui necessidades, físicas, psicológicas, sociais

e pessoais, como todo e qualquer ser humano. É por intermédio do professor que se formam as diversas profissões, deste modo é necessário que a sociedade e as instituições 
de ensino superior estejam unidas na construção do conhecimento, e que o professor seja reconhecido com agente mediador no processo de ensino/aprendizagem.

Neste sentido, a trama de fios que tece as costuras entre educação e saúde, permeiam o princípio de indissociabilidade das condições de trabalho docente sobre e a condição de saúde, demonstrando a necessidade de reorganização e o redimensionamento das atividades desempenhadas pelos professores com foco na saúde destes profissionais e a consequente melhorar da qualidade do trabalho por eles desempenhado e que atinge a toda a sociedade.

Buscamos aqui refletir brevemente sobre alguns temas e questionamentos sobre o papel do professor universitário e as suas condições de saúde e trabalho tais como, a necessidade de políticas públicas de apoio a este profissional oferecendo assim, insumos para futuras pesquisas. Trata-se de uma pequena ação na tentativa de grandes mudanças.

\section{REFERÊNCIAS}

AMARO, J. M. R. S.; DUMITH, S. C. Sonolência diurna excessiva e qualidade de vida relacionada à saúde dos professores universitários. J Bras Psiquiatr, v. 67, n. 2, p. 94$100,2018$.

BORSOI, I. C. F. Trabalho e produtivismo: saúde e modo de vida de docentes de instituições públicas de Ensino Superior. Cadernos de Psicologia Social do Trabalho, v. 15, n. 1, p. 81-100, 2012.

BRASIL. Ministério da Saúde (MS). Lei 8080, de 19 de setembro de 1990. Lei sobre as condições para a promoção, proteção e recuperação da saúde, a organização e o funcionamento dos serviços. Disponível em: https://www2.camara.leg.br/legin/fed/lei/1990/lei-8080-19-setembro-1990-365093normaatualizada-pl.pdf. Acesso em: 26 Dez. 2019.

CRUZ, R. M. et al. Saúde docente, condições e carga de trabalho. Revista Electrónica de Investigación y Docencia (REID), v. 4, n. 1, p.147-160, 2010.

DEMO, P. Metodologia para quem quer aprender. Atlas, São Paulo-SP, 2008.

DOS SANTOS, M. P. G., DA SILVA, K. K. D. Níveis de estresse e qualidade de vida de professores do ensino superior. Revista de Enfermagem da UFSM, v. 7, n. 4, p. 656-668, 2017.

DOS SANTOS SOUZA, A. et al. Fatores associados à qualidade de vida no trabalho entre professores do ensino superior. Arquivos de Ciências da Saúde, v. 22, n. 4, p. 46-51, 2015.

GUILHARDI, H. J. Auto-estima, autoconfiança e responsabilidade. Comportamento 
humano: tudo (ou quase tudo) que você precisa saber para viver melhor. Orgs.: Maria Zilah da Silva Brandão, Fatima Cristina de Souza Conte, Solange Maria B. Mezzaroba. Santo André, SP: ESETec Editores Associados, 2002. p. 63-98.

KOETZ, L. E. Qualidade de vida de professores de Instituições de Ensino Superior Comunitárias: relações entre ambiente e saúde. 2011. Dissertação de Mestrado. Disponível em: https://www.univates.br/bdu/bitstream/10737/250/1/LydiaKoetz.pdf. Acesso em: 12 jul. 2019.

LEDA, D. B.; MANCEBO, D. REUNI: Heteronomia e precarização da universidade e do trabalho docente. Educação \& Realidade, v. 34, n. 1, p. 49-64, 2009.

LOPES, M. C. R. " Universidade produtiva" e trabalho docente flexibilizado. Estudos e Pesquisas em Psicologia, v. 6, n. 1, p. 35-48, 2006.

MERCADO, L. P. L. et al. Formação docente e novas tecnologias. In: IV Congresso RIBIE, Brasília. 1998. Disponível em: $<$ http://www.educacional.com.br/upload/dados/materialapoio/71170001/5275731/FOR MA\%C3\%87\%C3\%830_DOCENTE_E_NOVAS_TECNOLOGIAS.pdf >. Acesso em: 22 ago. 2019.

NAHAS, M.V. Atividade Física, Saúde e Qualidade de vida. 3 ed. Londrina: Midiograf, 2003.

OSPINA, G. L. Definição de uma agenda para o ensino superior nos anos 90. In: Crub. Universidade, Estado e sociedade na década de 90. Brasília, 1990.

PIMENTA, S. G.; ANASTASIOU, L. das G. C.; CAVALLET, V. J. Docência no ensino superior: construindo caminhos. Formação de educadores: desafios e perspectivas. São Paulo: UNESP, p. 267-278, 2003.

PIMENTA, S. G. (Org.). Saberes Pedagógicos e Atividade Docente. Editora Cortez: São Paulo. $8^{\text {a }}$ edição, 2012.

PRIESS, F. G. Características do estilo de vida e da qualidade de vida dos professores universitários de instituições privadas de Foz Iguaçu e região. 2012. Disponível em: https://acervodigital.ufpr.br/handle/1884/26495. Acesso em: 08 jul.2019.

ROHDE, C. L. C. Qualidade de vida no trabalho sob a perspectiva de professores de ensino superior.2012. Disponível em: https://repositorio.ufsm.br/handle/1/10305. Acesso em: 08 jul.2019.

SELIGMANN-SILVA, E. Trabalho e desgaste mental: o direito de ser dono de si mesmo. São Paulo: Ed. Cortez, 2011.

SILVA, R. Características do estilo de vida e da qualidade de vida de professores do ensino superior público em Educação Física. 2006. Disponível em: https://repositorio.ufsc.br/handle/123456789/103127. Acesso em: 08 jul. 2019. 
SOLIGO, V. A ação do professor e o significado das avaliações em larga escala na prática pedagógica. IN: WERLW, Flávia Obino Corrêa (Org.). Avaliação em larga escala: foco na escola. Oikos - São Leopoldo; Liber Livro -Brasília, 2010, p.119-132.

SORATO, L.; OLIVIER-HECKLER. Os Trabalhadores e seu Trabalho. In CODO, W. (coordenador). Educação: carinho e trabalho. Petrópolis, RJ: Vozes / Brasília:

Confederação Nacional dos Trabalhadores em Educação; Universidade de Brasília. Laboratório de Psicologia do Trabalho, 1999.

SLEUTJES, M. H. S. C. Refletindo sobre os três pilares de sustentação das universidades: ensino-pesquisa-extensão. Revista de Administração Pública, v. 33, n. 3, p. 99-101, 1999.

ZABALZA, M. A. O ensino universitário: seu cenário, seus protagonistas. Tradução Ernani Rosa. Porto Alegre: Artmed, 2004.

\section{Recebido em: 01/06/2021}

Aprovado em: 20/06/2021

Publicado em: 30/06/2021 